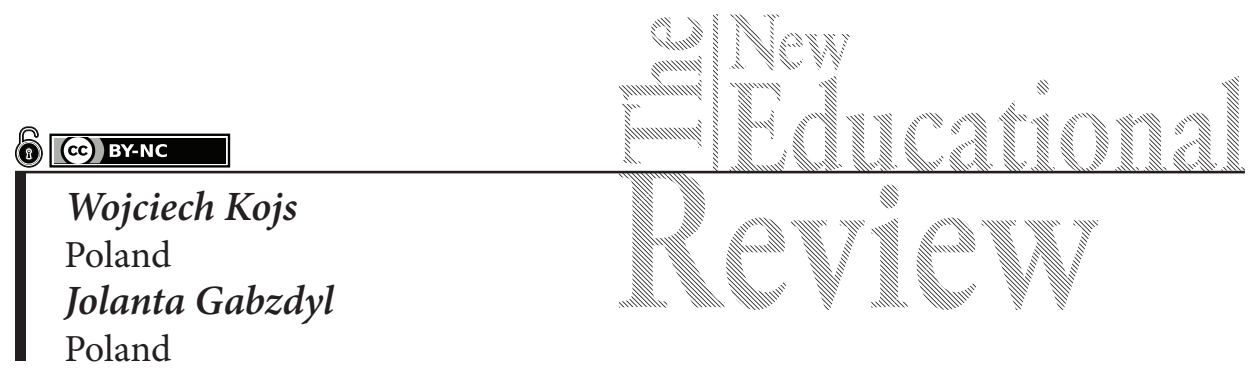

\title{
Questions in Textbooks and Lessons - Comparative Analysis
}

DOI: 10.15804/tner.2020.59.1.15

\begin{abstract}
The aim of the article was to conduct a comparative analysis of the structures and functions of didactic tasks, in the form of questions appearing in school textbooks and during lessons. Qualitative and quantitative analysis of the content of textbooks and lesson transcripts of lessons were carried out. The obtained data revealed differences that appeared between properties of didactic tasks of this kind found in early school textbooks and lessons. The presented research results will be used for subsequent research related to other types of didactic tasks, and may also contribute to enriching teachers' knowledge about the ways that pupils work with a textbook.
\end{abstract}

Key words: textbook, lesson, didactic task, structure and function of a question, early school education.

\section{Introduction}

Questions are necessary elements of didactic communication processes. Treated as language messages (Kövacses, 2006) from school textbook authors and teachers directed at pupils, they are to lead pupils to activities which activate them and that accompany the processes of education: changes in their mental and emotional resources. Together, such messages help the objectives of education and upbringing to be achieved. Their structure indicates expressions that trigger actions or, so-called, task operators and objects (items) to which these activities are to be 
directed. Questions are assigned to specific strategies, goals and educational concepts. They determine the course and final results of the teaching-learning process of pupils and the processes of their control and assessment (Kojs, 2019; Knissarina, Aganina, Bashbayeva, Zame \& Shaikhimov, 2016; Malik, \&. Chaudry, 2013; Uljens, 1994); the use of them leads to the formation of particular personality traits in pupils, and not others.

In considering questions as sentence messages, it is important to clearly distinguish their ontological essence as activities and products and to indicate the cognitive (epistemological) possibilities related to this distinction (Hintikka, 1976). Questions as language products are thoughts, desires, resolutions, intentions, etc. included in words which are available to sensory observation. They can be perceived sensorily - observed, analyzed, and interpreted (cf. e.g. Betti, 2016; Gabzdyl, 2012).

Questions occur, among others in the form of interrogative sentences. They include operators and objects which have desiderative or recommending functions (Brożek, 2008; Osbeck, 2018). As an inseparable and natural element of the educational process, which is revealed in almost every contact of students with teachers, as well as with school textbooks - questions are more or less related to pupils' intellectual activity and to their search for the answers the questions asked for. A good question is the essence of good teaching, as it makes a bridge between teaching and learning. It is a stimulator of the intellect because it stimulates what Piaget called cognitive conflict, thanks to which the child moves to a higher stage of development. According to Bruner's definition, it is the scaffold for learning (Fisher, 1995; Cohen, Manion \& Morrison, 1996). So, it is justified to constantly undertake research on the real properties of didactic tasks in the form of questions, and in particular, to take into account those which occur in the education process at the level of early school education (in grades 1 to 3 of primary school).

\section{Methodology of Research}

\section{General Background of Research.}

The object of research was didactic facts in the form of questions, including their operators in the form of interrogative pronouns but omitting imperative sentences used to replace questions (see Kojs \& Gabzdyl, 2016), which appear in school textbooks and in the course of naturally occurring school lessons. Due to the slightly different nature of the functioning of the selected research objects - "not embedded/embedded" in the contexts of didactic communication, only 
questions fulfilling cognitive functions (intellectual and intellectual-material) were adopted; questions of organizational, order, disciplinary nature, etc. were omitted.

The goal was to determine the role of these questions, and especially the role of their operators in the didactic process. The focus of the research were the problems expressed in the following questions: What is the structure and what functions are carried out by questions, including their operators, appearing in the studied school textbooks and lessons addressed to pupils? How do the structures and functions of these questions relate to each other?

\section{Research Sample}

Didactic tasks addressed to pupils of grades 1 and 3 of primary school were examined: from textbooks: 2322 questions (grades 1: 790, grades 3: 1524); from stenographic records of lesson: 6809 questions (grades 1: 3293, grades 3:3516).

The mentioned statistical data relate to 68 textbooks (grade 1: 46; grade 3: 22) and 60 stenographic records of lessons (30 in each grade).

\section{Instruments and Procedures}

Two types of documents were used in the study. The first was textbooks approved for school use by the Ministry of National Education in 2000-2016. Practice Exercise books, worksheets, etc. were not included, as preliminary qualitative analyzes revealed that the questions contained in them were mainly used to consolidate messages and train pupils' skills. The second type of document was transcripts of lessons, which were made in the years 2012-2014 and had been used in a different way as a part of other research (see Kojs \& Gabzdyl, 2016).

Adopting an understanding of questions as a specific language "product" consisting of an operator and an object/objects allowed us to perform, in a similar way, analysis of the content of textbooks and stenographic records. Therefore, at the stage of collecting and recording the raw data, a method of analyzing the content of the above-mentioned documents was adopted, while at the stage of their development, a qualitative and quantitative analysis using descriptive statistics measures was done.

\section{Data Analysis}

The questions taken from the content of textbooks/ lesson transcripts served as units for qualitative and quantitative analyses, including operators (activities) in the form of interrogative pronouns and the declination forms combined with appropriate prepositions. The question operators below are marked in italics to clearly distinguish them from objects. 
The collected data were classified as simple and complex, as well as complete and incomplete question structures, and illustrated with relevant examples. On this basis, 131 question operators were distinguished and from them a group of the 10 most common question operators was selected (see Table). They subsequently underwent comparative analyses to distinguish and interpret their educational functions.

The calculations were carried out using the statistical package StatSoft. Inc. (2014), STATISTICA (data analysis software system), version 12.0. and the Excel spreadsheet. Chi-square independence tests were used for qualitative variables (respectively using Yates correction for cell numbers below 10, checked for Cochran conditions, and an exact Fisher test). $\mathrm{p}=0.05$ was taken as the level of significance.

\section{Results of Research}

\section{Simple Structures}

Answering the research question regarding question structures, we begin with the characteristics of simple structures. In textbooks, simple interrogative structures generally first included a language expression constituting of a (single) operator, and afterward, a language expression (expressions) constituting a (single) object, e.g.:

- What shall we pay attention to?

- What does the taste of dishes depend on?

In turn, the questions formulated by teachers did not always first include question operators before objects specifying their meanings. It happened quite often that first there were objects, then operators, or operators separated the question objects into two parts, e.g.:

- The plant has a root, what for?

- Activity name, what part of speech is it?

\section{Complex Structures}

Questions with a complex structure were found in both the textbooks studied and in transcripts of the lessons. The complexity of this type of question is that with one and the same question operator there are several different connecting objects, or vice versa, the same question object connects several different operators. Seemingly, it gives the impression of the occurrence of only one question, but in reality, there are several different questions - as the examples below show: 
- What other rhymes and counting-out rhymes do you know? - What other rhymes do you know? What other counting-out rhymes do you know?

- Who needs a weather forecast and what for? - Who needs a weather forecast? What do you need a weather forecast for?

In both textbooks and in class, to a lesser extent, there were other complex questions: capturing at least one object and at least two operators - with the second and subsequent operator specifying the sense of the first one and it was "brought down" to the role of the object, e.g.:

- Can you say why these works are sculptures? - (1:) Can you say (2:) why these works are sculptures?

- What do you think, what are the rooms at the back of the theater for? (1:) What do you think, (2:) what are the rooms for, (3:) at the back of the theater?

\section{Incomplete Structures}

When speaking about incomplete question structures, we have in mind the partial or total omission of the object(s), as well as the total omission of operators. There was quite often a partial omission of question objects in the textbooks and lessons analyzed. In turn, questions with a total omission of objects were noted sporadically in the case of textbooks, but could be seen much more often in the course of the lessons studied. Instead of constructing full messages using words and phrases, i.e. questions consisting of at least one operator and object, teachers used contexts (especially language, task-based). For instance: the operator why (in the case of absence of an object) depending on the language context meant:

- Why (do you like the bookmark you have chosen)?

- Why (is the word "mane" written with the use of "e")?

At the same time, regardless of the object (context), the operator "demanded" pupils perform intellectual activities in the form of explanations.

The total omission of operators, which were primarily noted in relation to the lessons studied, appeared only sporadically in textbooks. The question operators in the form of the particle "whether" was an operator most often overlooked by teachers. In this type of question it was determined that there was a lack of the operator whether and not of another, from the question of the (opened) complement (e.g. what, who, where, how, etc.)? Thus, it was suggested by both linguistic contexts (students' answers: "yes", "no", or eventually "I don't know" - accepted by teachers) and the intonation of the language constructs of objects, i.e. suggesting the form of a question. 


\section{Educational Functions}

131 types of question operators were distinguished from the studied textbooks and transcripts of the lessons. They include various types of pronouns combined with various types of prepositions, which have different declination forms, e.g.:

- what: what onto, what against, what for, because of what, what into, what behind etc.;

- what with: what is on, what about, what is after, what is at, what is in, what is with, what is behind etc.;

- how: till what kind of, on what kind of, in what kinds of etc.;

- who: whose, whom, who for, who to, because of whom, by whom, who about, who with etc.;

- which: of which, to which, by which, from which, near which, in which (pl), from which etc.;

- how many: up to how many, how much for, in how many, from how many etc.

Due to the large linguistic diversity of the individual operators the Table lists the 10 most commonly distinguished types of question operators. They were referred to in early childhood education levels (grades 1 and 3 of primary school).

Table. The collation of the number of types of question operators: textbook authors and teachers - grades 1 and 3 of primary school

\begin{tabular}{|c|c|c|c|c|c|c|c|c|c|c|c|}
\hline \multirow{3}{*}{ No. } & \multirow{3}{*}{$\begin{array}{c}\text { Types of } \\
\text { operators }\end{array}$} & \multicolumn{5}{|c|}{ Textbook authors } & \multicolumn{5}{|c|}{ Teachers } \\
\hline & & \multicolumn{2}{|c|}{ grade 1} & \multicolumn{2}{|c|}{ grade 3} & \multirow{2}{*}{ P-value } & \multicolumn{2}{|c|}{ grade 1} & \multicolumn{2}{|c|}{ grade 3} & \multirow{2}{*}{ P-value } \\
\hline & & $\mathrm{n}$ & $\%$ & $\mathrm{n}$ & $\%$ & & $\mathrm{n}$ & $\%$ & $\mathrm{n}$ & $\%$ & \\
\hline 1 & what & 167 & 20.9 & 282 & 18.5 & 0.1602 & 717 & 21.8 & 771 & 21.9 & 0.8772 \\
\hline 2 & what of & 28 & 3.5 & 32 & 2.1 & 0.0421 & 23 & 0.7 & 22 & 0.6 & 0.7112 \\
\hline 3 & whether & 60 & 7.5 & 111 & 7.3 & 0.8366 & 723 & 22.0 & 823 & 23.4 & 0.1531 \\
\hline 4 & what with & 25 & 3.1 & 41 & 2.7 & 0.5422 & 50 & 1.5 & 75 & 2.1 & 0.0590 \\
\hline 5 & why & 46 & 5.8 & 77 & 5.1 & 0.4670 & 168 & 5.1 & 142 & 4.0 & 0.0355 \\
\hline 6 & where & 15 & 1.9 & 24 & 1.6 & 0.5871 & 71 & 2.2 & 65 & 1.8 & 0.3649 \\
\hline 7 & how & 110 & 13.8 & 223 & 14.6 & 0.5797 & 295 & 9.0 & 380 & 10.8 & 0.0107 \\
\hline 8 & $\begin{array}{l}\text { what kind } \\
\text { (m., sing.) }\end{array}$ & 16 & 2.0 & 53 & 3.5 & 0.0472 & 91 & 2.8 & 81 & 2.3 & 0.2271 \\
\hline 9 & $\begin{array}{l}\text { what kinds } \\
\text { (fem., pl) }\end{array}$ & 78 & 9.8 & 113 & 7.4 & 0.0494 & 182 & 5.5 & 273 & 7.8 & 0.0002 \\
\hline 10 & who & 17 & 2.1 & 42 & 2.8 & 0.3629 & 368 & 11.2 & 320 & 9.1 & 0.0045 \\
\hline 11 & others & 236 & 29.6 & 526 & 34.5 & 0.0160 & 605 & 18.4 & 564 & 16.0 & 0.0108 \\
\hline
\end{tabular}


Among the question operators listed in the Table, the operator in the form of the interrogative pronoun what appeared most frequently (in total, the textbook authors and teachers formulated them 1937 times) - however, in the case of teachers, it came second (after the operator whether). The operator what replaces the noun and - like the operator who (see Table) - allows general information about the objects marked by these pronouns to be obtained. It can replace the question operators which are "correct" in indicating the reasons why (the Table and the following example concern determining the reasons for something), as well as (not included in Table:) what for, for what purpose, for what reason, why.

The uniqueness of the pronoun what is that it belongs to the most universal of question operators, because together with the appropriate object, it can cause a variety of different, or similar information activities, e.g.:

- Determining the content, meanings of terms, concepts (including the definition of the essence of things), e.g. What is a family tree? What shall we show as an example of "open composition"? What do you feel holding this paper in your hands?

- Determining the means (including tools, equipment, and materials) and methods for specific purposes, e.g. What shall we need to build a similar house? What can children do to help animals in winter?

- Indicating appropriate norms, rules of conduct, e.g. What should you do if you do not know how to write these words? What do you need for removing plugs from contacts safely? What are the duties of the pupil on duty in the classroom?

- Determining the causes (including genesis) of phenomena, events, processes, e.g. What caused the sudden braking of the vehicle? What makes the mood of this poem sadder, more gloomy?

- Indicating the goals, functions of things, processes, events, e.g. What was the purpose of our trip? What is used for vacuuming?

- Determining the effects, consequences (including prediction, etc.) of phenomena, events, processes, e.g. What would happen if the Earth ran out of water? What will change when we turn the globe? What can you do with an empty water bottle?

- Indicating relationships, compounds, dependencies between things, phenomena, events, and processes, e.g. What does a plant need to live? What pollutes our waters?

- Determining the belonging of the given things, phenomena, events, and processes to certain groups, e.g. What grows the lowest in the forest? What is associated with warmth in nature? 
- About comparing (indicating similarities and differences) of things, phenomena, events, and processes, e.g. What do photos representing a bench, chair, stool, and armchair have in common? What connects the two parts of the story?

Concerning the textbooks, the percentages for the discussed operator what in grades 1 and 3 are $20.9 \%$ vs. $18.5 \%(p=0.1602)$. In grade 3 , the percentage for the operator what was significantly lower for the textbooks compared to teachers $(\mathrm{p}=$ 0.0060 ). In turn, the percentages concerning teachers who include the operator who in questions in grades 1 and 3 are $11.2 \%$ vs. $9.1 \%(\mathrm{p}=0.0045)$; in grade 1 the percentage was significantly higher. In grade 1 , the percentage for the operator who was significantly lower for textbooks compared to teachers $(p=0.0001)$, while in grade 3 this percentage was significantly lower for textbooks compared to teachers $(\mathrm{p}=0.0001)$. Concerning the operator why - which is so important in modeling cause-and-effect thinking for younger school children - the percentages of teachers examined in grades 1 and 3 are $5.1 \%$ vs. $4.0 \%(\mathrm{p}=0.0355)$, and in grade 1 this percentage was significantly higher. For the operator what of - the percentages of the textbooks in grades 1 and 3 are $3.5 \%$ vs. $2.1 \%(\mathrm{p}=0.0421)$, and in grade 1 the percentage was significantly higher. In grades 1 and 3 , the percentages were significantly higher for textbooks compared to teachers $(\mathrm{p}=0.0001)$. In turn, for the operator what with - in grade 1 the percentage was significantly higher for textbooks compared to teachers $(\mathrm{p}=0.0001)$.

The interrogative particle whether - which is an element of "closed" questions (for decisions) was also an operator very often used in teachers' questions $(22.0 \%$ and $23.4 \%$ ). The function of the operator whether is special because it allows each complement question to be transformed into the form of simple alternatives. Answering these types of questions, students most often stated something about objects and relationships occurring outside them, based on their knowledge which, in conjunction with the large number of these questions, may suggest a significant part of the early school education process. At the same time, there were no statistically significant differences in grades 1 and 3 . And in relation to the textbooks, which (compared to teachers) used the operator whether much less often $(7.5 \%$ and $7.3 \%)$ - in grades 1 and 3 the percentage for the operator whether was significantly lower for textbooks in comparison with teachers $(p=0.0001)$.

The table contains question operators that perform the same function: what kind (m., sing.), what kinds (fem., pl). Additionally, they were separated from another operator: what kind (fem., sing.) (not included in the Table). The pronouns what kind (m., sing.) / what kind (fem., sing.) / what kinds (fem., pl) that replace adjectives, determine the quality of a noun, or relation to the determined noun. As 
part of a question, an answer regarding the features of the object or relationship is expected - e.g. "what kind (m., sing.)/what kind (fem., sing.)/what kind (fem., $\mathrm{pl}$ ) of $[\ldots]$ is something". The percentages of the operator what kind (m., sing.) for textbooks in grades 1 and 3 are $2.0 \%$ vs. $3.5 \%(\mathrm{p}=0.0472)$; while in grade 3 the percentage was significantly higher. In grade 3 , the percentage for the operator what kind (m., sing.) was also significantly higher in comparison with teachers (p $=0.0173$ ). In turn, the percentages in textbooks for the operator what kind (fem., pl) in grades 1 and 3 are $9.8 \%$ vs. $7.4 \%(p=0.0494)$ with the percentage significantly higher in grade 1 . The percentages for teachers in grades 1 and 3 are $5.5 \%$ vs. $7.8 \%(p=0.0002)$; while in grade 3 the percentage was significantly higher. At the same time, in grade 1, the percentage for the operator what kind (fem., pl) was significantly higher for textbooks when compared to teachers $(\mathrm{p}=0.0001)$.

The operator how was also used quite often both by the teachers surveyed and by the textbooks. The adverb how in questions is used to mean that the answer should include verb definitions, e.g. in relation to the questions: how do we get to know..., how do you think..., how do you suggest..., how do you like... - which is also especially valuable in the modeling of pupils' cognitive skills. The percentages for teachers who formulate questions with the operator how in grades 1 and 3 are $9.0 \%$ vs. $10.8 \%(\mathrm{p}=0.0107)$; with the percentage significantly higher in grade 3 . At the same time in grade 1, the percentage for the operator how was significantly higher for textbooks compared to teachers $(\mathrm{p}=0.0001)$, as in grade 3 .

The percentages for teachers regarding other operators in grades 1 and 3 are $18.4 \%$ vs. $16.0 \%$ ( $\mathrm{p}=0.0108)$; with the percentage significantly higher in grade 1 . In addition, in grades 1 and 3 , the percentage of other operators was significantly higher for textbooks compared to teachers $(\mathrm{p}=0.0001)$.

\section{Conclusion}

The conducted research reveals issues relevant both from the point of view of theory and practice of education which relates not only to the level of early school education. Namely, questions, and in particular, their operators, properly separated and juxtaposed, can be used:

1. as systems of measurable, comparable and at the same time simple (uncomplicated) indicators; as so-called "quick indicators", in contrast to many different indicators, which allow the quick and quite accurate definition and evaluation of education concepts which have been taught, including the value and significance of the level of implemented goals and tasks; 
2. to create systems/models of question operators needed to achieve specific goals.

It would be beneficial if the early school system/model of question operators in textbooks and used by teachers included important educational functions, especially how to shape cognitive skills such as description, explanation, and prediction. Combining the analysis of questions with the analysis of other types of questions, it will be possible in the future to significantly enrich the diagnosis of the state of early school education, to define its needs and directions for development more closely, including developing concepts to support the work of teachers and students when using textbooks.

\section{References}

Betti, A. (2016). Kazimierz Twardowski, In N. Zalta (Ed.) The Stanford Encyclopedia of Philosophy (Summer 2019 Edition), https://plato.stanford.edu/archives/sum2019/ entries/twardowski/.

Brożek, A. (2008). Pytania i odpowiedzi. Analiza krytyczna koncepcji Kazimierza Ajdukiewicza [Questions and Answers. Critical analysis of Kazimierz Ajdukiewicz's concept.]. Zagadnienia Filozoficzne w Nauce, XL (2), 137-168.

Cohen, L., Manion, L. \& Morrison, K. (1996). Guide to Teaching Practice. London and New York: Routledge.

Fisher, R. (1995). Teaching Children to Learn. Stanley Thornes (Publishers) Ltd.

Gabzdyl, J. (2012). Szkice do prakseodydaktycznej teorii celów, poleceń i pytań w kształceniu wczesnoszkolnym [Sketches for the praxeodidactic theory of goals, instructions and questions in primary school education.]. Racibórz: PWSZ.

Hintikka, J. (1976). The Semantics of Questions and the Questions of Semantics. Acta Philosophica Fennica, 28 (4).

Knissarina, M.M., Aganina, K.Zh., Bashbayeva, M.A., Zame, J. \& Shaikhimov, Y. (2016). Development of Regulatory Skills in Younger School Pupils. The New Educational Review, 44 (2), 165-175.

Kojs W. (2019). The Educational Value of Control and Evaluation Activities. The New Educational Review, 57 (3), 103-114.

Kojs, W. \& Gabzdyl, J. (2016). Questions Hidden in School Children's Responses - Structure and Didactic Functions. The New Educational Review, 45 (3), 89-101.

Kövacses, Z. (2006). Language, Mind, and Culture: A Practical Introduction. Oxford: Oxford University Press.

Malik, S.K. \& Chaudry, M.A. (2013). Concept building of Elementary Level through Activity-Based Instruction, The New Educational Review, 31 (1), 17-27.

Osbeck, Ch. (2018). Questions and speech genres in social studies classrooms. Comparisons of communication patterns. In Didactic classroom studies. A potential research direction (pp. 23-45), Lund: Nordic Academic Press.

Uljens, M. (1994). A study on the foundations of cognitivism. Vasa: Via Mathesis Press. 